\title{
The Comparative Study of the Structure and Phase Composition of Ni-Based Coatings Modified by Plasma Jet or Electron Beam
}

\begin{abstract}
D. Alontseva*, A. Russakova and A. Krasavin
East-Kazakhstan State Technical University, 69 Protozanov St, Ust-Kamenogorsk, 070004, Kazakhstan

The paper deals with the results of the comparative study into the structure and phase composition, as well as some properties (microhardness, corrosion resistance) of Ni-based powder coatings before and after their modification by DC electron beam or DC pulse plasma jet, according to the modes recommended on the basis of model calculations of the temperature profiles at irradiation. The transmission electron microscopy and Xray analysis have revealed that irradiation leads to an increase in the volume fraction of reinforcing nanosized intermetallic components in the coatings. There were established certain similarities and differences in the structure and properties of the coatings modified by different types of irradiation. The microhardness of the irradiated coatings has increased in both cases along with the growth of the volume fraction of the $\mathrm{CrNi}_{3}$ particle phase. However, it was found that the diffusion zone in the coatings modified by plasma jet is higher than that of the coatings modified by electron irradiation. The coating surface melted by the electron beam has a marked reduction of its roughness and better homogenization of the microstructure therefore demonstrating better adhesion and corrosion resistance.
\end{abstract}

DOI: 10.12693/APhysPolA.129.838

PACS/topics: 81.15.-z, 81.07.-b, 68.47.Gh

\section{Introduction}

At present the technologies of surface modification by plasma jets or electron beams replace longer thermal treatment because they allow to change the structure of surface layers of treated materials within a short exposure period [1,2], so they are booming all over the world. Practical experience with these technologies shows the results in the formation of surface layers with improved performance characteristics (micro or nanostructures with high hardness, heat-resistance, corrosion and wear resistance) [2-6].

The coatings under investigation represent powder coatings deposited, in one case, by a plasma jet onto a steel substrate, and then processed by a plasma jet in air; and in the other case by an electron beam in vacuum. The processing modes of the plasma jet, as well as the electron beam, were selected according to mathematical modeling of temperature profiles formed in twolayer metallic absorbers (coating-substrate) while heated by a moving source of radiation. The modes selected (the source power density, the travel speed of the electron beam or plasma jet along the coating surface) are believed to lead to the formation of a certain temperature profile [6-8]. It was assumed that the prediction of temperature distribution in the coating area adjacent to the substrate makes possible the selection of such modes of treatment that will provide precipitation of specific phases from the solid solution, as well as acceleration

*corresponding author; e-mail: dalontseva@mail.ru of the diffusion processes between the coating and the substrate. These, in their turn, increase hardness of the coatings and improve the adhesion to the substrates. We also expected to fuse the coating surface to reduce its roughness. Thus we expected to obtain a modified coating with increased hardness, and good corrosion resistance. The outcomes of the comparative study of the two different ways of modification of the same coating provide grounded implications for potential industrial use of these technologies. The results of the study were correlated to the analogous data for the same coating before modification.

The aim of this work was to compare the results of modification of Ni-based protective powder coating by a plasma jet and an electron beam. The comparative research is carried out in order to provide evidence-based recommendations on the selection of appropriate types and modes of additional irradiation of protective powder coating if it is necessary to improve their performance characteristics.

\section{Materials and methods}

The studied material is PG-10N-01 (Ni-based powder alloy with additives of $\mathrm{Cr}(8-14 \%)$, B $(2.3 \%)$, Si $(1.2-$ $3.2 \%)$, Fe (5\%), C (0.5\%)) deposited onto the steel St3 (Fe - base, C - 0.25\%, Mn - 0.8\%, Si $-0.37 \%$, $\mathrm{P}<0.045 \%)$ substrate by a plasma jet. The modes of deposition of this coating were described in detail in our papers $[4-6,8]$.

The hardening of the coating under investigation, as it was established experimentally $[4,6]$, is due to precipitation inside it of the intermetallic phases of lamellar morphology at heating and deformation. The form of 
precipitation of reinforcing nanoparticles from a solid solution is determined by thermodynamically favored cellular precipitate of supersaturated solid solution with fcc-type (face-centered cubic lattice) of crystal lattice under conditions far from equilibrium (high temperature, deformation) [2,9]. The layers with nanostructure in the form of lamellar intermetallics developed in the coatings should have improved heat resistance, just due to the presence of intermetallic compounds, which are known [10] to retain their structure and properties at elevated temperatures. These layers are also characterized by high hardness $[4,6]$.

Modifying irradiation of the samples was carried out according to the following design modes:

- irradiation of the Ni-based coated samples in the vacuum (better than $4 \mathrm{~Pa}$, but no better than $0.4 \mathrm{~Pa}$ ) by the $\mathrm{DC}$ (direct current) electron beam source using "U-212" source with an accelerating voltage of $30 \mathrm{kV}$; the power density of the electron beam is $5 \times 10^{6} \mathrm{~W} / \mathrm{m}^{2}$, the speed of the electron beam is $0.004 \mathrm{~m} / \mathrm{s}$.

- irradiation of the Ni-based coated samples by a pulsed plasma jet using "Pulse-6" in the air: the power density of the plasma jet is $1.9 \times 10^{9} \mathrm{~W} / \mathrm{m}^{2}$, pulse duration is $10 \mu \mathrm{s}$, the pulse repetition frequency is $2.5 \mathrm{~Hz}$, the travel speed of the plasma jet is $0.006 \mathrm{~m} / \mathrm{s}$.
Experimental methods of analysis include Transmission Electron Microscopy (TEM) by JEM-2100 ("JEOL", Japan), Scanning Election Microscopy (SEM) by JSM-6390LV ("JEOL", Japan) with Energy Dispersive Spectrometry (EDS) ("Oxford Instruments", Great Britain), Atomic Force Microscopy (AFM) by NT206 (Belorussia), X-ray diffraction (XRD) by X'Pert PRO ("PANalytical", the Netherlands). Microhardness test of the samples was performed with LM-700 digital microhardness meter (LECO, Russia). Corrosion was tested using the potentiostatic method to measure the sea-water corrosion rate.

\section{Results and discussion}

It was established by TEM and XRD methods that the structure and phase composition of the irradiated coatings in both cases is similar (Table I). The coating is mainly composed of crystallographically disoriented nanograins of Ni-based solid solution with the fcc type of crystal lattice (Fig. 1), which precipitate as nanoscale lamellae of the $\mathrm{CrNi}_{3}$ intermetallic phase with the same fcc structure (Fig. 2).

Additional irradiation, as expected, leads to an increase in the volume fraction of these particles in average by $5 \%$ during processing both by plasma and electron beam (Table I).

TABLE I

Phase composition and $R a$ of the Ni-based coating (PG-10N-01) before and after irradiation.

\begin{tabular}{|c|c|c|}
\hline \multicolumn{3}{|c|}{$\begin{array}{l}\text { Volume concentration [\%]. Chemical formula. Crystal system. Space group. } \\
\text { Space group number. Parameters }[\AA]\end{array}$} \\
\hline before irradiation & after irradiation by e-beam & after irradiation by plasma jet \\
\hline $\begin{array}{c}65 \% \text { \|solid solution on } \\
\text { Ni-base (-phase) } \| \\
\text { cubic \|Fm-3m\| } \\
(225) \| a=3.59-3.60\end{array}$ & $\begin{array}{c}74 \% \text { \|solid solution on } \\
\text { Ni-base (-phase) } \| \\
\text { cubic } \| \text { Fm-3m } \| \\
(225) \| a=3.5(8)\end{array}$ & $\begin{array}{c}70 \% \text { \|solid solution on } \\
\text { Ni-base (-phase) } \| \\
\text { cubic } \| \text { Fm-3m\| } \\
(225) \| a=3 .(59)\end{array}$ \\
\hline $\begin{array}{c}15 \%\left\|\mathrm{CrNi}_{3}\right\| \\
\text { cubic }\|\mathrm{Fm}-3 \mathrm{~m}\| \\
(225) \| a=3.5520\end{array}$ & $\begin{array}{c}20 \%\left\|\mathrm{CrNi}_{3}\right\| \\
\text { cubic }\|\mathrm{Fm}-3 \mathrm{~m}\| \\
(225) \| a=3.552\end{array}$ & $\begin{array}{c}20 \%\left\|\mathrm{CrNi}_{3}\right\| \\
\text { cubic }\|\mathrm{Fm}-3 \mathrm{~m}\| \\
(225) \| a=3.552\end{array}$ \\
\hline $\begin{array}{c}10 \%\left\|\mathrm{FeOCr}_{2} \mathrm{O}_{3}\right\| \\
\text { cubic }\|\mathrm{Fd}-3 \mathrm{~m}\| \\
(227) \| a=8.3440\end{array}$ & $\begin{array}{c}3 \%\left\|\mathrm{FeNi}_{3}\right\| \\
\text { cubic }\|\mathrm{Fm}-3 \mathrm{~m}\| \\
(225) \| a=3.5556\end{array}$ & $\begin{array}{c}4 \%\left\|\mathrm{FeOCr}_{2} \mathrm{O}_{3}\right\| \\
\text { cubic }\|\mathrm{Fd}-3 \mathrm{~m}\| \\
(227) \| a=8.3440\end{array}$ \\
\hline $\begin{array}{c}10 \%\|\mathrm{NiO}\| \\
\text { cubic }\|\mathrm{Fm}-3 \mathrm{~m}\| \\
(225) \| a=4.2\end{array}$ & $\begin{array}{c}3 \%\left\|\mathrm{Fe}_{7} \mathrm{Ni}_{3}\right\| \\
\text { cubic }\|\mathrm{Im}-3 \mathrm{~m}\| \\
(229) \| a=2.861\end{array}$ & $\begin{array}{c}4 \%\|\mathrm{NiO}\| \\
\text { cubic }\|\mathrm{Fm}-3 \mathrm{~m}\| \\
(225) \| a=4.2\end{array}$ \\
\hline & & $\begin{array}{c}2 \%\left\|\mathrm{FeNi}_{3}\right\| \\
\text { cubic }\|\mathrm{Fm}-3 \mathrm{~m}\| \\
(225) \| a=3.5556\end{array}$ \\
\hline \multirow{2}{*}{\multicolumn{3}{|c|}{ Average values of coating surface roughness $R a, \mu \mathrm{m}$}} \\
\hline 0.20 & & 0.10 \\
\hline
\end{tabular}



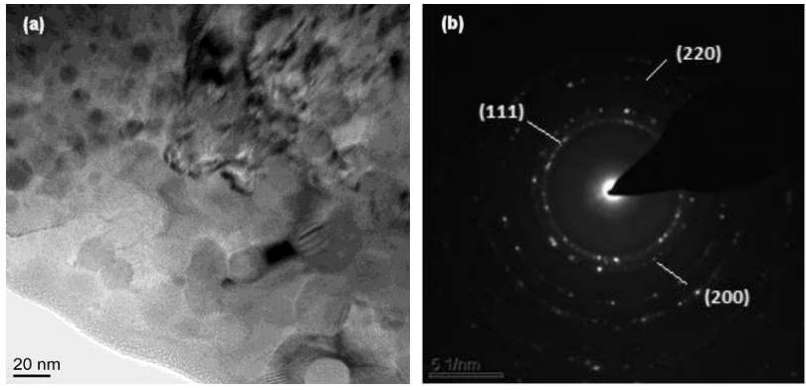

Fig. 1. TEM images of the Ni-based irradiated coatings (a), corresponding diffraction pattern (b).
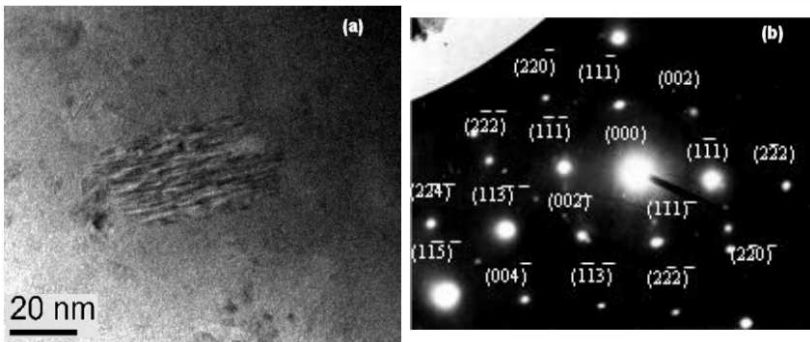

Fig. 2. TEM images of the Ni-based coating irradiated by the plasma jet: the $\mathrm{CrNi}_{3}$ particles (a) and their diffraction pattern (b).
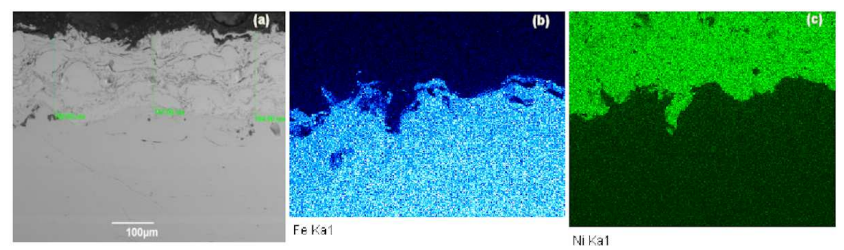

Fig. 3. The image of the cross-section of the PG-10N01 coating on the steel substrate after irradiation by plasma jet (a) and the corresponding map of the $\mathrm{Ni}(\mathrm{b})$ and $\mathrm{Fe}(\mathrm{c})$ distribution in the coating and the substrate.

However, there are the following marked differences in the structural-phase composition of the exposed coatings. Firstly, the irradiated with the plasma jet coating contains some oxides; it has a smaller amount of compounds of $\mathrm{Ni}$ with Fe than the electron beam irradiated coating. Secondly, the surface roughness of the electron beam irradiated coating is substantially lower, though the melting of the coating at the upper part is observed in both cases; the surface roughness is also reduced in both cases (Table I). Thirdly, not completely melted large powder particles are left in the coating after the plasma treatment (Fig. 3a). In general, as shown in Fig. 3a, the microstructure of the coating in this case is sufficiently homogeneous, and no cracks are observed at the boundary of the coating with the substrate. SEM with EDS techniques have revealed that at both electron irradiation and plasma jet treatment there is a process of rapid mutual penetration of the base material of the Ni coating into the substrate, and $\mathrm{Fe}$, the main component of the substrate, into the coating (Fig. 3b, 3c). The interpenetration in such processes is so deep (up to $200 \mu \mathrm{m}$ ), that the radiation-enhanced diffusion processes can be assumed [11]. The rate of diffusion in this case is believed to depend on the type of radiation; it is higher at the pulsed nature of the exposure. In particular, we observed this effect at the irradiation by a direct current electron beam, but the depth of interpenetration of elements did not exceed $100 \mu \mathrm{m}$ (width of the diffusion zone).

The microhardness of the irradiated coatings on the whole has increased by $25 \%$ (from $6.2 \mathrm{GPa}$ in the initial coating to $7.8 \mathrm{GPa}$ in the irradiated ones) in both cases, which is associated with the increase in the volume fraction of the $\mathrm{CrNi}_{3}$ particle phase (Table I).

The decrease of the coatings roughness and the acceleration of diffusion processes at the border of the coating and the substrate (and, respectively, improved adhesion) are accompanied by a natural increase in corrosion resistance of the coatings modified by electron irradiation. Corrosion resistance in seawater increases even in comparison with the analogous values for the same coating modified by the plasma jet (Table II). Before modification the PG-10N-01 coating had such a poor adhesion, that it was not possible to carry out the corrosion test, because coating had been peeling off along the boundary with the substrate.

TABLE II

The results of corrosion resistance tests in $3 \% \mathrm{NaCl}$ solution.

\begin{tabular}{c|c|c|c|c}
\hline \hline Materials & $\begin{array}{c}E \\
{[\mathrm{mV}]}\end{array}$ & $\begin{array}{c}i_{\text {cor }} \\
{[\mathrm{mA}]}\end{array}$ & $\begin{array}{c}i_{\text {pas }} \\
{[\mathrm{mA}]}\end{array}$ & $\begin{array}{c}E_{\text {pas }} \\
{[\mathrm{mV}]}\end{array}$ \\
\hline $\begin{array}{c}\text { PG-10N-01 coating } \\
\text { after plasma } \\
\text { jet modification }\end{array}$ & -300 & 0.92 & 1.0 & 1170 \\
$\begin{array}{c}\text { PG-10N-01 coating } \\
\text { after electron } \\
\text { beam modification }\end{array}$ & -300 & 0.89 & 0.8 & 1090
\end{tabular}

\section{Conclusions}

The types of strengthening micro and nanostructures formed in the coatings when modified by the plasma jet or electron beam are similar. The increased microhardness is achieved by increasing the volume fraction of intermetallic nanoscale particles of lamellar morphology with the fcc structure released from the polycrystalline solid solution with the same fcc structure. In both cases the penetration of $\mathrm{Ni}$ from the coating into the substrate, and Fe from the substrate into the coating is marked. This effect is more pronounced in the case of pulsed plasma irradiation, when the depth of mutual penetration of the elements (diffusion zone) reaches about $200 \mu \mathrm{m}$ (while at the DC electron beam irradiation it does not exceed $100 \mu \mathrm{m}$ ). The irradiation by the electron beam causes melting of the coating surface, thus leading to a considerable reduction in its roughness, up to 3 -fold (while at the plasma 
irradiation it is not more than 2-fold), and more marked fusion penetration of powder coating particles (homogenization of the microstructure), which is accompanied by an observable increase in resistance to corrosion, better than in the case of plasma modification.

\section{References}

[1] J.M. Poate, G. Foti, D.C. Jacobson, Surface Modification and Alloying by Laser, Ion, and Electron Beams Press, Springer US, New York 1983.

[2] K. Kadyrzhanov, F. Komarov, A. Pogrebnyak, Ionbeam and Ion-Plasma Modification of Materials Press, MGU, Moscow 2005.

[3] Yu.F. Ivanov, E.V. Nadeikin, J. Rus. Phys. 8/2, 402 (2009).

[4] D.L. Alontseva, S.N. Bratushka, M.V. Il'yashenko, M.V. Makhmudov, N.V. Prokhorenkova, Phys. of Metal and Metallography 113(8), 785 (2012).
[5] D.L. Alontseva, A.L. Krasavin, A.D. Pogrebnjak, A.V. Russakova, Acta Phys. Pol. A 123, 867 (2013).

[6] D.L. Alontseva, A.D. Pogrebnjak, T.A. Kolasnikova, A.V. Russakova, Mater. Sci. 19(3), 277 (2013).

[7] A.L. Krasavin, D.L. Alontseva, N.F. Denisova, Certificate of Authorship No. 0010558 of the Republic of Kazakhstan for the Computer Program (entry in the register number 1151 of August 20, 2013).

[8] D.L. Alontseva, A.L. Krasavin, T.A. Kolesnikova, A.V. Russakova, Acta Phys. Pol. A 125, 1275 (2014).

[9] V.F. Sukhovarov, The Cellular Precipitation in Alloys Press, Nauka, Novosibirsk 1983.

[10] I.A. Kurzina, E.V. Kozlov, Y.P. Sharkeev, Nanocrystalline intermetallic and Nitride Structures Formed During Ion-Beam Exposure Press, NTL, Tomsk 2008.

[11] F.V. Nolfi, Phase Transformation during Irradiation Press, Metallurgiya, Chelyabinsk 1989. 